\title{
Stiction in surface micromachining
}

\author{
Niels Tas $\nmid$, Tonny Sonnenberg, Henri Jansen, Rob Legtenberg \\ and Miko Elwenspoek
}

MESA Research Institute, University of Twente, PO Box 217, 7500 AE Enschede, The Netherlands

Received 29 August 1996

\begin{abstract}
Due to the smoothness of the surfaces in surface micromachining, large adhesion forces between fabricated structures and the substrate are encountered. Four major adhesion mechanisms have been analysed: capillary forces, hydrogen bridging, electrostatic forces and van der Waals forces. Once contact is made adhesion forces can be stronger than the restoring elastic forces and even short, thick beams will continue to stick to the substrate. Contact, resulting from drying liquid after release etching, has been successfully reduced. In order to make a fail-safe device stiction during its operational life-time should be anticipated.

Electrostatic forces and acceleration forces caused by shocks encountered by the device can be large enough to bring structures into contact with the substrate. In order to avoid in-use stiction adhesion forces should therefore be minimized. This is possible by coating the device with weakly adhesive materials, by using bumps and side-wall spacers and by increasing the surface roughness at the interface. Capillary condensation should also be taken into account as this can lead to large increases in the contact area of roughened surfaces.
\end{abstract}

\section{Introduction}

Stiction is a notorious cause of malfunctioning in microdevices. Surface micromachined structures which have been fabricated using the wet sacrificial layer etching technique can be pulled down to the substrate by capillary forces during drying $[1,2]$. In recent years, much attention has been paid to avoiding contact during drying. Section 4 gives an overview of the methods which have been developed. Analysis of the adhesion mechanisms [3,4] shows that stiction may occur whenever flexible and smooth structures are brought in contact with the substrate (sections 2 and 3). Therefore, in-use stiction should be anticipated. In section 5, two possible causes of contact during the operation of devices are analyzed: electrostatic attraction and acceleration forces. Incidental contact during operation can not always be excluded. Furthermore, devices are made where contact between moving parts is desirable [5,6]. It is important to minimize adhesion forces in this case either by reducing the contact area or by changing the surface properties. This is analyzed in section 6 . In section 6 results of stiction reduction by using self-aligned robust side-wall spacers are also presented.

\section{Origins of stiction}

Adhesion of contacting surfaces has been studied extensively in tribology. Stiction phenomena are observed in hard-disk systems where the roughness of the contacting surfaces approaches nanometer scale. Adhesion

$\dagger$ email: n.r.tas@eltn.utwente.nl. mechanisms have also been studied for wafer bonding purposes where stiction of contacted surfaces is desirable. Surface roughness plays an important role in adhesion. Surface micromachined structures are often very flat. Legtenberg [7] measured an RMS roughness between 1 and $3 \mathrm{~nm}$ at the bottom of released structures, depending on polysilicon and sacrificial (PECVD) silicon oxide thicknesses. The roughness of silicon wafer surfaces has been measured for bonding purposes. RMS roughness is typically below $1 \mathrm{~nm}[8,9]$. The real contact area (RCA) can be a large fraction of the apparent contact area between these structures. In the first analysis of adhesion mechanisms, we assume that the contacting surfaces are perfectly flat. The influence of surface roughness will be analyzed in section 6.3. Four adhesion mechanisms, which play an important role in stiction of surface micromachined structures, are discussed: capillary forces, hydrogen bridging, electrostatic forces and van der Waals forces [7].

\subsection{Capillary forces}

A thin liquid layer between two solid plates can work as an adhesive. If the contact angle $\theta_{C}$ between liquid and solid is less than $90^{\circ}$ (figure 1), the pressure inside the liquid drop will be lower than outside and a net attractive force between the plates exists.

The pressure difference $\Delta p_{l a}$ at the liquid-air interface is given by the Laplace equation [10]:

$$
\Delta p_{l a}=\frac{\gamma_{l a}}{r}
$$




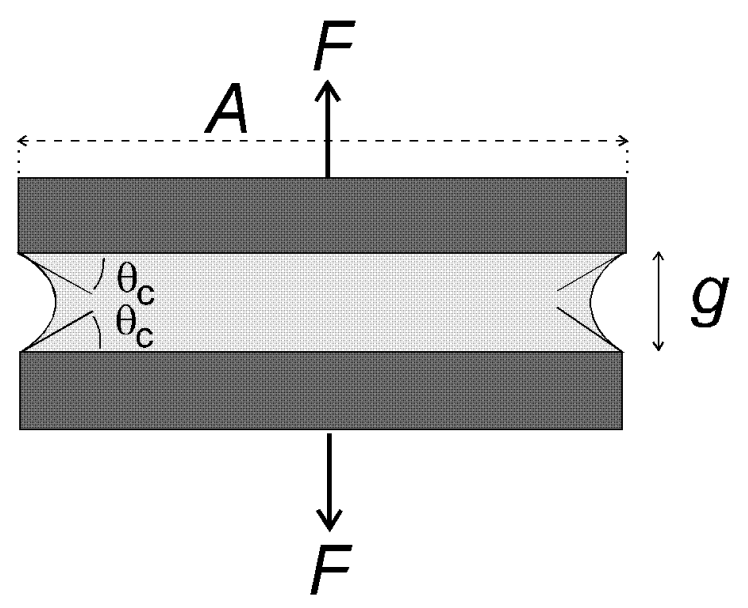

Figure 1. A thin layer of liquid working as an adhesive between two plates. $\theta_{C}$ is the contact angle between liquid and solid in air, $g$ is the liquid layer thickness, and $A$ is the wetted area. A force $F$ is applied to maintain equilibrium.

where $\gamma_{l a}$ is the surface tension of the liquid-air interface, and $r$ is the radius of curvature of the meniscus (negative if concave). In figure 1 , the liquid is between the plates and the liquid contacts the solid at the fixed contact angle. From simple geometry it follows that $r=-g / 2 \cos \theta_{C}$. In equilibrium, an external force $F$ separating the plates must be applied to counterbalance the capillary pressure forces:

$$
F=-\Delta p_{l a} A=\frac{2 A \gamma_{l a} \cos \theta_{C}}{g}
$$

where $A$ is the wetted area. Note that a positive force $F$ corresponds to a negative Laplace pressure. The pressure inside the liquid is lower than outside and the plates are pushed together by pressure forces. For stiction calculations it is convenient to calculate the surface energy stored at the interface that is bridged by a drop of liquid [2]. Consider a drop of liquid placed on a solid, surrounded by air (figure 2). In equilibrium, the contact angle between liquid and solid is determined by the balance between the surface tensions of the three interfaces. This balance is expressed by Young's equation [10]:

$$
\gamma_{s a}=\gamma_{s l}+\gamma_{l a} \cos \theta_{C} \quad 0<\theta_{C}<\pi
$$

where $\gamma_{s a}$ is the surface tension of the solid-air interface and $\gamma_{s l}$ is the surface tension of the solid-liquid interface. Young's equation is also valid for configurations other than that of figure 2. The contact angle is the same on a curved or irregular shaped surface, inside a capillary etc.

If the solid-air surface tension is smaller than the sum of the liquid-air and solid-liquid surface tensions, then the contact angle is larger than $0^{\circ}$ and the liquid will be nonspreading (figure 3).

If the solid-air surface tension is larger than the sum of the liquid-air and solid-liquid surface tensions, then it will be energetically favorable for the liquid to spread. The contact angle will be equal to $0^{\circ}$. A drop bridging two surfaces will form thin liquid films outside the bridged area (figure 4).

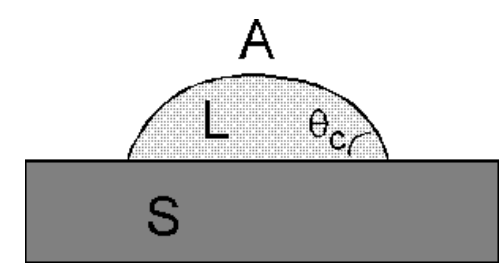

Figure 2. Liquid drop (L) on a solid (S), in air $(A) \cdot \theta_{C}$ is the contact angle between liquid and solid in air.

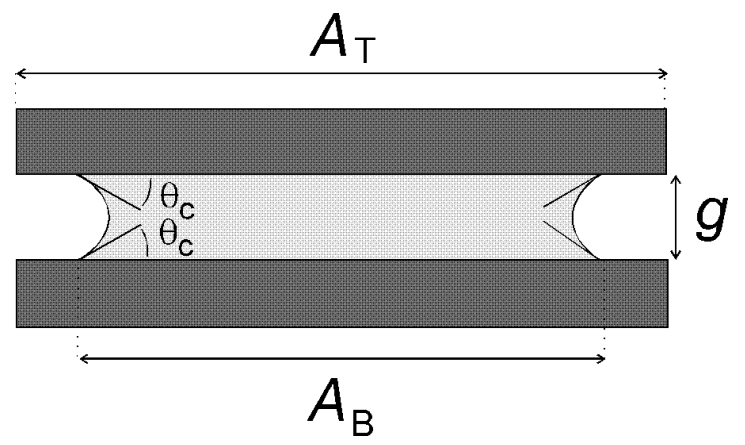

Figure 3. Liquid bridging two solids. The liquid is non-spreading. The solid is only covered in the bridged area $A_{b} . A_{t}$ is the total facing area.

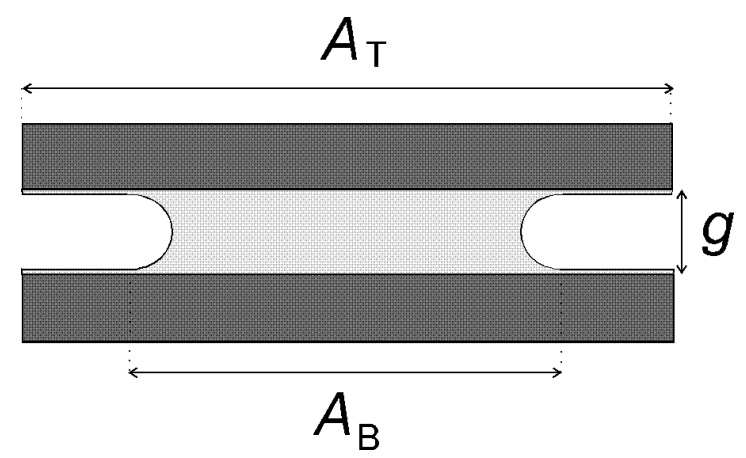

Figure 4. Liquid bridging two solids. The liquid is spreading. Outside the bridged area $A_{b}$, a thin liquid film covers the solid.

The total surface energy of the area between the plates can be calculated by adding the surface tensions of the solid-air, solid-liquid and liquid-air interfaces [2]. It is assumed that the liquid is confined to a bridged area $A_{b}$, which is smaller than or equal to the total facing areas $A_{t}$. (4a) expresses the surface energy in the case of a spreading liquid, $(4 b)$ that for a non-spreading liquid:

$$
\begin{aligned}
E_{s}= & 2\left[A_{t}\left(\gamma_{s l}+\gamma_{l a}\right)-A_{b} \gamma_{l a}\right]=2\left[A _ { t } \left(\gamma_{s l}\right.\right. \\
& \left.\left.+\gamma_{l a}\right)-A_{b} \gamma_{l a} \cos \theta_{C}\right] \\
E_{s}= & {\left[A_{t} \gamma_{s a}-A_{b}\left(\gamma_{s a}-\gamma_{s l}\right)\right]=2\left[A_{t} \gamma_{s a}\right.} \\
& \left.-A_{b} \gamma_{l a} \cos \theta_{C}\right] .
\end{aligned}
$$

In $(4 a, b)$ the energy of the liquid-air meniscus area is neglected, which is a fair assumption if the gap $g$ between the plates is small, so that the meniscus area is small compared to the bridged area. The total area $A_{t}$ and the surface tensions are constant. Therefore, the total surface energy as a function of the bridged area can be written in 


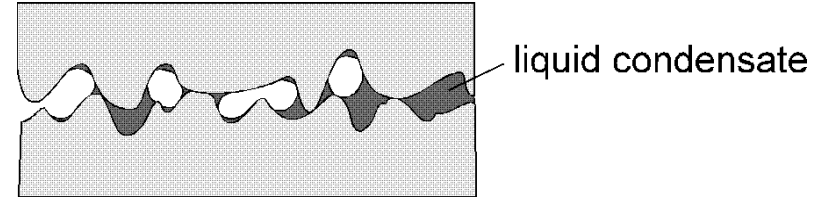

Figure 5. Capillary condensation between two contacting surfaces. The meniscus curvatures are equal to the Kelvin radius; the contact angles satisfy Young's equation.

a general form, which is valid for both the spreading and the non-spreading condition [2]:

$$
E_{s}=C-2 A_{b} \gamma_{l a} \cos \theta_{C}
$$

where $\gamma_{l a} \cos \theta_{C}$ is the adhesion tension, and $C$ takes into account the constant terms in $(4 a, b)$. The importance of liquid mediated adhesion is supported by both stiction and friction experiments. Stiction of released structures can show a large dependence on the relative humidity of air [11]. Friction measurements of silicon and silicon compounds [12] show a strong dependence of the static friction coefficient on relative humidity. In macrotribology it is well known that adhesion of solids can strongly depend on relative humidity [13]. This is caused by capillary condensation. Liquids that wet or have a small contact angle on surfaces will spontaneously condense into cracks, pores, and into small gaps surrounding the points of contact between the contacting surfaces. At equilibrium the meniscus curvature is equal to the Kelvin radius [10]:

$$
r_{K}=\frac{\gamma_{l a} V}{R T \log \left(p / p_{s}\right)}
$$

where $V$ is the molar volume, $p$ is the vapor pressure and $p_{s}$ is the saturation vapor pressure. At room temperature, $\gamma_{l a} V /(R T)=0.54 \mathrm{~nm}$ for water [10]. The meniscus curvature strongly depends on the relative vapor pressure $p / p_{s}$. For a relative humidity of $50 \%$ we find $\log \left(p / p_{s}\right)=$ -0.69 and $r_{k}=-0.8 \mathrm{~nm}$. At $100 \%$ relative humidity, $\log \left(p / p_{s}\right)=0$ and $r_{k}=\infty$ which means that a water film can grow all over the surface. The amount of condensed liquid in thermodynamic equilibrium is determined by both the Kelvin radius and the contact angle. The meniscus curvatures are equal to the Kelvin radius and the contact angles satisfy Young's equation (figure 5).

Capillary condensation can lead to a large increase in the RCA of solids by means of liquid bridging. It can, therefore, drastically increase the adhesion of those solids that due to their roughness show a low adhesion in a dry environment [13]. Models for the adhesion force due to capillary condensed liquid have been developed in harddisk tribology [14-16].

\subsection{Hydrogen bridging}

Hydrophilic silicon surfaces, under atmospheric conditions and temperatures well below $200{ }^{\circ} \mathrm{C}$, contain adsorbed water layers. When two of these hydrated surfaces are brought into close contact, hydrogen bonds may form between oxygen and the hydrogen atoms of the adsorbed water layers. Stengl et al [17] have calculated an adhesion energy of about $100 \mathrm{~mJ} \mathrm{~m}{ }^{-2}$ based on this bonding model. From wafer bonding experiments $[18,19]$ and stiction experiments $[4,20]$, adhesion energies between 60 and $270 \mathrm{~mJ} \mathrm{~m}^{-2}$ have been reported for hydrophilic surfaces $\left(T<200^{\circ} \mathrm{C}\right)$.

\subsection{Electrostatic forces between mobile charges}

Electrostatic attractive forces across the interface can arise from a difference in work functions or from electrostatic charging of opposed surfaces [21, 18,22]. Difference in the work function leads to the formation of an electrical double layer by a net transfer of electrons from one surface to the other. Contact potentials are generally below $0.5 \mathrm{~V}$, and the resulting surface charge densities are smaller than $10^{13}$ elementary charges per square centimetre [21]. At small separations the electrostatic pressure between flat surfaces is generally lower than the van der Waals pressure [21]. Temporary charging can occur during processing [22] or operation. Examples of this are tribocharging of rubbing surfaces [15] and charge accumulation in insulators of electrostatic operated micromotors [23]. Permanent stiction is not expected due to these effects because the non-equilibrium charging will relax in time.

\subsection{Van der Waals forces}

The van der Waals dispersion forces between two bodies are caused by mutual electric interaction of the induced dipoles in the two bodies. Dispersion forces generally dominate over orientation and induction forces except for strongly polar molecules [24]. The interaction energy per unit area due to van der Waals interaction between two flat surfaces in the non-retarded regime $(d<20 \mathrm{~nm})$ is given by [10]

$$
E_{v d W}=-\frac{A}{12 \pi d^{2}}
$$

where $A$ is the Hamaker constant and $d$ is the distance between the surfaces. For most solids and liquids, the Hamaker constant lies in the range $0.4-4 \times 10^{-19} \mathrm{~J}$ [10]. For surfaces in contact a cut-off distance of $d=d_{0}$, slightly smaller than the interatomic distance, should be used to calculate the adhesion energy. Using a universal cut-off distance of $d_{0}=0.165 \mathrm{~nm}$ and Hamaker constants calculated by the Lifshitz theory, a good agreement between experimental values and adhesion energies calculated with equation (6) is found for non-hydrogen-bonding, nonmetallic solids and liquids [10]. Equation (6) with $d=d_{0}$ can be used to predict the adhesion energy of a clean hydrophobic silicon surface. However, the adhesion energy strongly depends on the surface termination. Often this is not exactly known. For pure silicon a Hamaker constant of $1.1 \times 10^{-18} \mathrm{~J}$ is given [21], yielding a adhesion energy of $1.1 \mathrm{~J} \mathrm{~m}^{-2}$ [10]. From wafer bonding literature [18] and stiction experiments [3,20], adhesion energies between 12 and $140 \mathrm{~mJ} \mathrm{~m}^{-2}$ are reported. The reported values may be much lower than the theoretical value due to hydrogen, fluorine or $\mathrm{CH}_{x}$ termination of the surface [18] and due to surface roughness. Compared to hydrophilic 


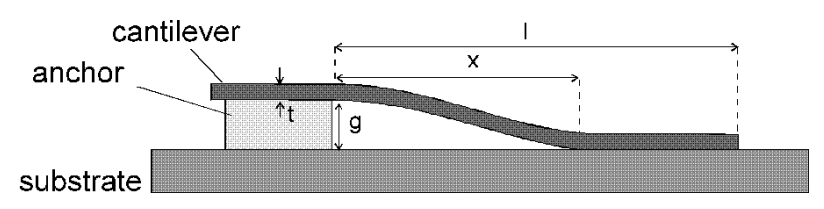

Figure 6. A cantilever beam of length / and thickness $t$, anchored at a initial gap spacing $g$. The beam attaches the substrate at distance $x$ from the anchor.

surfaces, the adhesion of hydrophobic surfaces might be more sensitive to surface roughness because smoothing by condensed water is absent.

\section{Critical dimensions of beams and membranes}

As soon as a structure touches the substrate, the total surface energy is lowered. The structure will permanently stick to the substrate if during peel-off the total energy of the system reaches a minimum. The total energy of the system consists of the elastic deformation energy and the surface energy, which is a constant minus the adhesion energy. This energy balance is easily made for a cantilever beam [3]. Figure 6 shows a cantilever beam of length $l$, thickness $t$ and width $w$, anchored at a initial gap spacing $g$.

The beam attaches to the substrate at diatance $x$ from the anchor. The elastic energy stored in the cantilever is given by

$$
E_{m}=\frac{E t^{3} g^{2} w}{2 x^{3}} .
$$

The surface energy as a function of the attachment length $l-x$ is given by

$$
E_{s}=C-\gamma_{s}(l-x) w
$$

where $\gamma_{s}$ is the adhesion energy per unit area. In equilibrium, the total energy $E_{m}+E_{s}$ is minimal. An equilibrium detachment length $x_{e q}$ can be found, where the decrease of the elastic energy is equal to the increase of the surface energy, by increasing the detachment length $x$ :

$$
\frac{\partial E_{m}}{\partial x}+\frac{\partial E_{s}}{\partial x}=0
$$

Substitution of (7) and (8) into (9) yields

$$
\frac{3}{2} \frac{E t^{3} g^{2} w}{x_{e q}^{4}}=\gamma_{s} w .
$$

The critical length of cantilever beams is smaller than the detachment length $x_{e q}$ because before complete detachment shear deformation at the tip will occur and the beam will touch the substrate under an angle [3]. The deformation energy at the point of snap back is about four times lower, and for the critical length can be written

$$
l_{\text {crit }}=\sqrt[4]{\frac{3}{8} \frac{E t^{3} g^{2}}{\gamma_{s}}} .
$$

If the residual stress and the stiffening due to stretching are neglected then the critical length of doubly clamped beams and the critical radius of circular membranes show the same dependence on $t, g, E$ and $\gamma_{s}$. Only the numerical constant in (11) should be changed, yielding a critical length of doubly clamped beams that is about 2.9 times larger and a critical radius of circular membranes that is about 2.4 times larger than the critical length of cantilevers [4]. To obtain an idea of the strength of adhesion, we can evaluate the critical length of cantilever and doubly clamped beams, assuming an adhesion energy $\gamma_{s}=100 \mathrm{~mJ} \mathrm{~m}^{-2}$ and a Young's modulus of $150 \mathrm{GPa}$. Figure 7 shows the length of the beams that are just kept down to the substrate, as a function of beam thickness, for three different gap spacings. The dotted line in figure 7(b) shows the critical length of doubly clamped beams, if stiffening due to stretching of the beam is taken into account [4]. Even at gap spacings that are four times the thickness of the beam $(t=1 \mu \mathrm{m}$, $g=4 \mu \mathrm{m})$, the critical length is only slightly increased by this effect.

The figure shows that even $10 \mu \mathrm{m}$ thick cantilevers with a large gap spacing of $4 \mu \mathrm{m}$, have a critical length of only $310 \mu \mathrm{m}$ (880 $\mu \mathrm{m}$ for doubly clamped beams). It is clear that stiction can easily cause malfunctioning in many devices. (11) shows that the critical length depends less than proportionally on the thickness, gap spacing and adhesion energy. A reduction factor of 16 in the adhesion energy only yields an increase in the critical length by a factor of two.

\section{Contact during fabrication}

After wet sacrificial layer etching the released structure is immersed in liquid. During the subsequent drying, structures are pinned down to the substrate by capillary forces. A theoretical description of these forces will be given in the next paragraph.

\subsection{Capillary forces of drying liquid}

Consider a beam with a thickness much greater than its width. In the final state of the drying process the liquid volume approaches zero. If the tip of the beam touches the substrate, a very small amount of liquid can bridge a large area underneath the beam by forming an inside meniscus, and pulling a part of the beam flat against the surface (figure 8). This is the state of lowest total energy as the liquid volume approaches zero.

The energy of adhesion by liquid bridging is found from equation $(4 c)$. This final state is only reached if (i) the tip touches the substrate and (ii) the surface energy plus the deformation energy has a minimum for a detachment length $x$ smaller than the beam length $l$ (see figure 8(a)). Condition (ii) can be analysed by the substitution of the adhesion energy of the liquid bridge per unit area, $2 \gamma_{l a} \cos \theta_{C}$, into equation (11). The critical length of cantilever beams to be adhered to the substrate by the final small amount of liquid is given by

$$
l_{\text {crit }}=\sqrt[4]{\frac{3}{16} \frac{E t^{3} g^{2}}{\gamma_{l a} \cos \theta_{c}}} .
$$

The critical length found by this analysis is almost the same as that found by Mastrangelo and Hsu [2]. Mastrangelo 


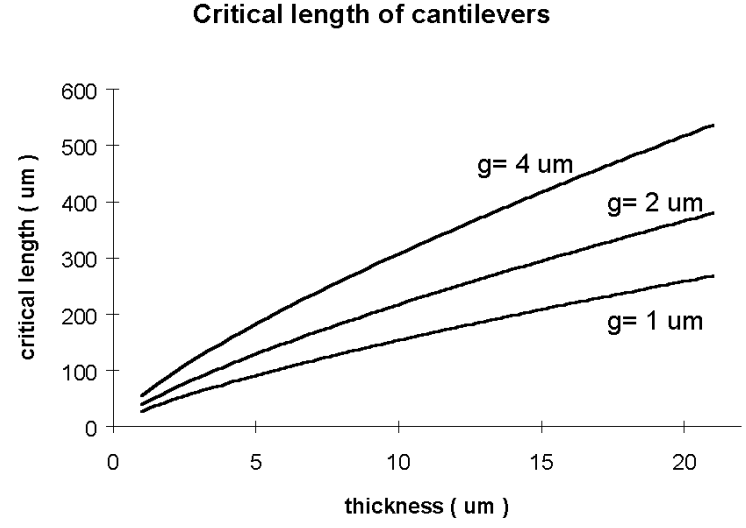

(a)

\section{Critical length of doubly clamped beams}

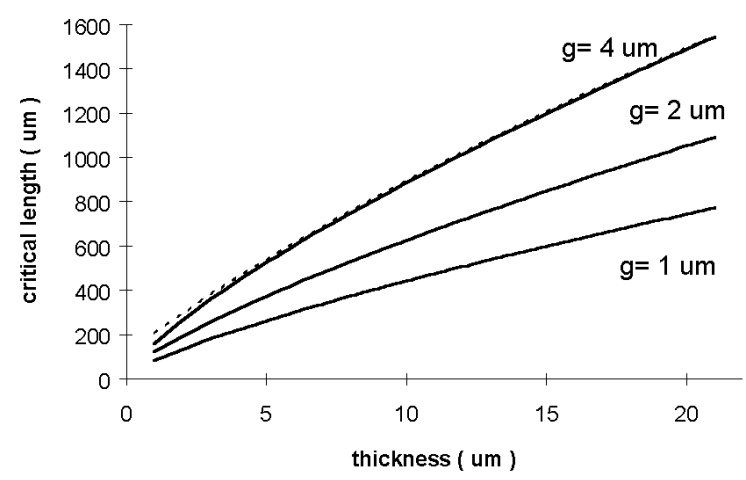

(b)

Figure 7. Critical lengths of cantilever beams (a) and doubly clamped beams (b), as a function of beam thickness for different gap spacings, according to equation (11). A Young's modulus of $150 \mathrm{GPa}$ and an adhesion energy of $100 \mathrm{~mJ} \mathrm{~m}^{-2}$ is assumed. Residual stress is neglected. The dotted line in (b) shows the critical length of doubly clamped beams if stiffening due to stretching of the beam is taken into account [4]. Beams shorter than the critical length will snap back after contacting the substrate.

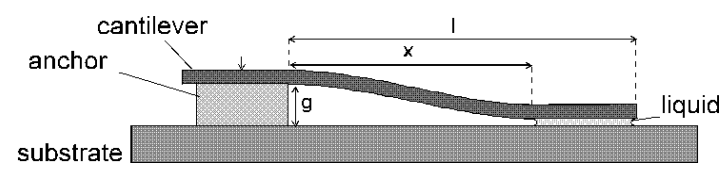

(a)

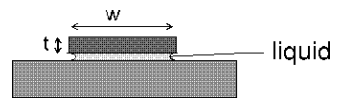

(b)

Figure 8. Final state of liquid drying underneath a cantilever beam: (a) side view; (b) front view. In the final state of drying a small amount of liquid can lower the surface energy by a great amount by bridging an area that is pulled flat against the substrate.

and Hsu modeled the complete drying trajectory to find out whether the tip would touch or not. If residual stresses

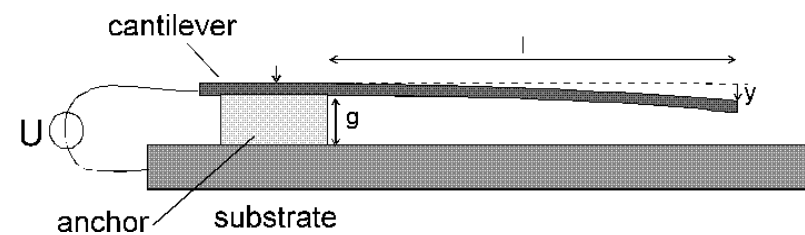

(a)

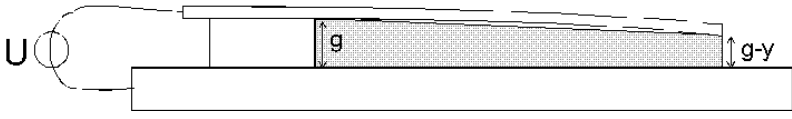

(b)

Figure 9. (a) Pull-down of a cantilever beam by electrostatic forces. $U$ is the applied voltage difference between the beam and the substrate, $g$ is the initial gap spacing, $I$ is the length of the beam, $t$ is the thickness and $y$ is the tip deflection. (b) The shaded region is the gap for which the capacitance is calculated.

and stiffening due to stretching are neglected, then the critical length of doubly clamped beams is about 2.5 times larger and the critical radius of circular membranes is about 1.7 times larger [2]. The critical length during peeloff calculated using (11) assuming an adhesion energy of $100 \mathrm{~mJ} \mathrm{~m}^{-2}$ and the critical length during drying calculated using (12) assuming an adhesion energy of $146 \mathrm{~mJ} \mathrm{~m}^{-2}$ (water; $20^{\circ} \mathrm{C} ; 0^{\circ}$ contact angle) are almost identical. Therefore figure 7(a) also applies to the latter case. The critical length of silicon cantilevers during the drying of water, assuming a thickness $t=5 \mu \mathrm{m}$, a Young's modulus $E=150 \mathrm{GPa}$ and a gap spacing $g=2 \mu \mathrm{m}$, equals $119 \mu \mathrm{m}$. This is too small for most applications. Pinning down can occur at significantly smaller lengths if structures are large at the tip and small at the base.

\subsection{How to avoid contact during drying}

Unless very thick or short structures and large gap spacings are used, it is not possible to avoid contact during drying by increasing the elastic deformation energy. Structures that stick can sometimes be released mechanically or by generating an repulsive force between the structures [25]. However, these methods do not seem to be suitable for batch processing. In general, it is more practical to avoid contact during the drying process. In the past 7 years different methods have been developed that allow fabrication of structures with thickness:length ratios of more than $1: 1000$.

The adhesion tension $\gamma_{l a} \cos \theta_{c}$ can be decreased choosing a low-surface-tension liquid for drying [11,26], or by adjusting the contact angle. Scheepers et al [11] report reduction of the stiction of silicon nitride beams after drying from $n$-hexane, which has a low surface tension $\left(19 \mathrm{~mJ} \mathrm{~m}^{-2}\right)$ compared to DI water $\left(73 \mathrm{~mJ} \mathrm{~m}^{-2}\right)$. By changing the combination of the surface materials and the liquid to be dried, one can try to obtain a contact angle near or over $90^{\circ}$. Only small negative, or even repulsive capillary pressures, result [27]. Abe et al [28], have tried to increase yield by drying at elevated temperatures because surface tensions decrease on increasing temperature. An additional mechanism of stiction reduction when drying at 
high temperatures may be cavitation in the liquid bridge $[13,29]$. If the vapor pressure at the drying temperature exceeds the pressure inside the liquid bridge (the pressure outside plus the Laplace pressure), the liquid may start to boil locally [13]. This will limit the negative capillary pressure.

Several methods have been proposed that apply temporary support to counteract the surface tensional forces during drying. Break-away polysilicon supports are used that have to be removed after release processing [30,31]. This can be done mechanically (probing) or by melting the supports [31]. Because the supports have to be removed one by one, application is limited to experimental devices. Batch-processing-compatible temporary supports have therefore been developed [32,33]. In both methods holes in the sacrificial layer are made to anchor the structures to be released to the substrate. Anchoring is achieved using a photoresist grid [33] or using polymer columns [32]. The maximum spacing between the supports is determined by the stiffness of the structures to be released [32]. After a complete sacrificial layer etch the supports are removed in oxygen plasma. Temporary supports are very effective in avoiding contact during drying. For example, Mastrangelo and Saloka [32] have fabricated plates measuring $3000 \times 3000 \times 1 \mu \mathrm{m}^{3}(1 \mu \mathrm{m}$ gap spacing $)$.

The drying process and its capillary forces can be avoided by using another physical process to get rid of the liquid. In the ordinary drying process, liquid evaporates and capillary forces arise as a result of the surface tension of the liquid-vapor interface. In the supercritical drying process, first reported by Mulhern et al [34], liquid is transferred to vapor via the supercritical phase. Carbon dioxide is used because of its low critical temperature and pressure $\left(T_{c}=31.1^{\circ} \mathrm{C}, p_{c}=72.8 \mathrm{~atm}\right)$. During evaporation of the supercritical carbon dioxide, no liquid-vapor interface exists, so there are no capillary forces working. Beams with a length of $850 \mu \mathrm{m}$ (1.4 $\mu \mathrm{m}$ thick, $2.7 \mu \mathrm{m}$ gap spacing) have been released [34]. Freeze drying as a liquid removing step was first applied to micromachining by Guckel et al [1]. After HF etch, the wafer is immersed in a watermethanol mixture. Next, the liquid surrounding the wafer is frozen by evaporation cooling in a vacuum chamber. The solid water-methanol is removed by sublimation at 0.15 mbar. The methanol has been added to avoid supercooling of the water as this can cause the water to freeze too rapidly. At MESA we now use sublimation of cyclohexane at about $-5^{\circ} \mathrm{C}$ [7]. The sublimation is performed at atmosperic pressure on a plate cooled by a Peltier element under a continuous flow of nitrogen. The nitrogen flow aids the sublimation process by removing the cyclohexane vapor. It also prevents condensation of water on the substrate. For the same reason the wafer is heated to room temperature after completion of the sublimation process. High-yield fabrication of cantilevers up to $1 \mathrm{~mm}$ in length ( $2 \mu \mathrm{m}$ thick; $2 \mu \mathrm{m}$ gap spacing) has been achieved.

Orpana and Korhonen [35] report the use of polymer support to avoid pull-down by drying liquid. After the HF etch a rinsing process starts in which the HF is gradually substituted by organic solvent. Finally the wafers are immersed in a photoresist-acetone mixture. The photoresist is solidified and can be stripped in a oxygen plasma. Kozlowski et al [36] developed a rinsing procedure in which the structures are finally immersed in divinylbenzene. This monomer is then solidified by polymerization under UV light. The release is completed by stripping the polymer in a oxygen plasma. High-yield release of $500 \mu \mathrm{m}$ long (500 nm thick: $900 \mathrm{~nm}$ gap spacing) cantilevers has been accomplished [36].

Methods that use a dry sacrificial etch step avoid the use of liquid completely. Silicon dioxide can be removed by etching in HF vapor [27]. Long ( $2 \mathrm{~mm})$ thin beams have been successfully released. The SCREAM process [37], as well as the BSM-one run [38] apply sacrificial layer etching of (poly)silicon. The SIMPLE process applies sacrificial layer etching of $\mathrm{n}^{+}$doped silicon [39]. A characteristic problem of these processes is the limited width of structures that can be underetched. Dry sacrificial layer etching is promising, especially when alternative structural materials and sacrificial layers [40] are considered.

\section{Contact during operation}

Stiction originating from the fabrication process has been reduced quite successfully. Fail-safe devices should be designed to avoid stiction of released structures during their operational life-time. Sources of contact strongly depend on the application of the device. An analysis of two possible source of in-use contact, electrostatic pull-down and pushdown by acceleration forces, follows.

\subsection{Electrostatic pull-down}

To further our understanding of the effect of electrostatic forces, we will firstly examine cantilever beams due to a voltage difference between the beams and the substrate, are pulled down to the substrate. The deflection of the beam is described by the following non-linear differential equation:

$$
E l \frac{\partial^{4} y(x)}{\partial x^{4}}=\frac{\varepsilon w U^{2}}{2(g-y(x))^{2}}
$$

where $y(x)$ is the deflection at position $x$ along the cantilever, $g$ is the initial gap to the substrate, $E l$ is the flexural rigidity of the beam, $\varepsilon$ is the permittivity, $w$ is the width of the beam and $U$ is the voltage difference between the beam and the substrate (figure 9). A full analytical solution can not yet be obtained. An approximate solution can be derived by looking at the total potential energy which consists of the electrical energy stored in the gap and the mechanical deformation energy stored in the beam. This can easily be done if a constant shape is assumed. The deflection function can only change in amplitude. The elastic deformation energy assuming the uniform load shape is a function of the tip deflection $y$ :

$$
E_{m}=\frac{48}{30} \frac{E l}{l^{3}} y^{2} .
$$

The capacitance between the beam and the substrate is calculated by assuming a linear shape between the tip and the anchor of the beam (figure 9(b)):

$$
C(y)=\frac{\varepsilon w l}{y} \ln \left|\frac{g}{g-y}\right| .
$$


Tip deflection as a function of the applied voltage $U$ can be found from the balance between the electrostatic pull-down force and the restoring elastic force:

$$
\frac{\partial E_{m}}{\partial y}=\frac{\partial E_{e}}{\partial y}
$$

where $E_{e}=\frac{1}{2} C(y) U^{2}$. The system becomes instable (pullin) if the pull-down force increases faster than the restoring elastic force with increasing $y$. The point of instability is therefore reached if

$$
\frac{\partial^{2} E_{m}}{\partial y^{2}}=\frac{\partial^{2} E_{e}}{\partial y^{2}} .
$$

Combination of equations (15)-(17) yields for the tip deflection at pull-in

$$
\ln \frac{g}{g-y}=\frac{y\left(g-\frac{4}{3} y\right)}{(g-y)^{2}}
$$

which gives $y_{p i}=0.44 g$. Substitution in equation (16) and combination with equation (14) gives for the pull-in voltage

$$
U_{p i}=\sqrt{0.22 \frac{E g^{3} t^{3}}{\varepsilon l^{4}}} .
$$

(19) slightly underestimates the pull-in voltage, because the capacity is overestimated using the linear deflection profile. The same procedure can be applied to obtain the pull-in gap and voltage for doubly clamped beams, neglecting the axial tensile stress. A convenient deflection function is $y(x)=(y / 2)(1-\cos (2 \pi x / l)$, where $y$ is the deflection in the middle of the beam and $l$ is the total length [41]. This way a pull-in deflection of $\frac{2}{5} g$ is found. An expression similar to (19) is found for the pull-in voltage as a function of $t, g, l$ and $E$. The numerical constant is equal to 12.1 instead of 0.22 and $l$ is the total length of the doubly clamped beam. Accurate calculations have been performed by Osterberg et al [42]. They found an analytical solution for beam and membrane pull-in voltages assuming a uniform load, and replaced the numerical constants in this solution by fitting parameters, which were obtained from numerical solutions of the differential equations. This way the non-uniform electrostatic load working on the deflected beam or membrane could be taken into account. In [42] the influence of residual stress and stiffening due to stretching of the doubly clamped beam and the membrane on the pullin voltage are incorporated in the model. If these effects are neglected a general expression for the pull-in voltage of cantilevers, doubly clamped beams and membranes similar to (19) is found [42]:

$$
U_{p i}=\sqrt{c \frac{E g^{3} t^{3}}{\varepsilon l^{4}}}
$$

where $l$ represents the total length in the case of cantilever and doubly clamped beams, and the radius in the case of a circular membrane. The value for $c$ according to Osterberg et al [42], for the three configurations, is given in table 1 .

Figure 10 shows pull-in voltages of cantilever beams as a function of $l$ for different beam thicknesses and initial gaps according to (19). A cantilever with a length of
Table 1. The numerical value for $c$ to be used in (20) for cantilevers, doubly clamped beams and circular membranes [42].

\begin{tabular}{lc}
\hline Configuration & $\begin{array}{c}\text { Numerical } \\
\text { constant } c\end{array}$ \\
\hline Cantilever & 0.28 \\
Doubly clamped beam & 11.9 \\
Clamped circular membrane $^{\mathrm{a}}$ & 2.27
\end{tabular}

a For circular membranes an effective Young's modulus $E /\left(1-v^{2}\right)$ should be used in (20), where $v$ is the Poisson ratio.

Pull-in voltage of cantilevers

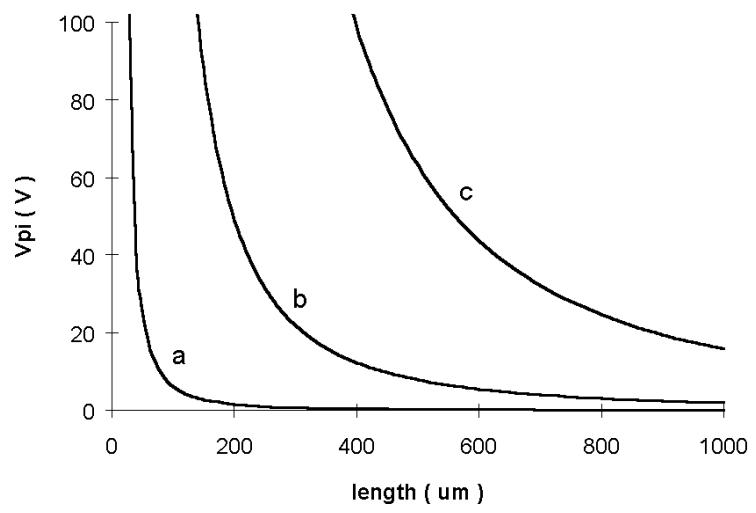

Figure 10. Pull-in voltage for a cantilever beam as a function of the length: (a) thickness $t=1 \mu \mathrm{m}$, initial gap spacing $g=1 \mu \mathrm{m}$; (b) $t=5 \mu \mathrm{m}, g=2 \mu \mathrm{m}$; (c) $g=4 \mu \mathrm{m}$, $t=10 \mu \mathrm{m}$

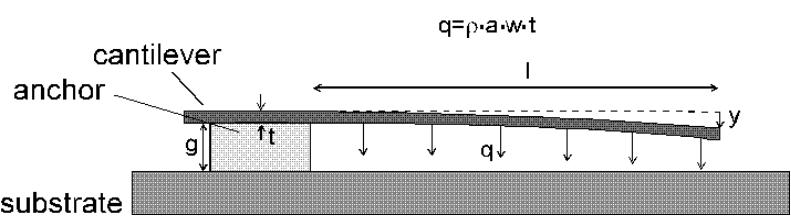

Figure 11. A cantilever beam deflecting under its own weight. Assume that the substrate is accelerated upward by $a\left(\mathrm{~m} \mathrm{~s}^{-2}\right)$. The beam is loaded by a force $q$ per unit length of $\rho$ awt, where $\rho$ is the density, $w$ is the width of the beam and $t$ is the thickness of the beam.

$100 \mu \mathrm{m}$, a thickness of $1 \mu \mathrm{m}$ and a gap spacing of $1 \mu \mathrm{m}$ is pulled to the substrate by a voltage difference of only 6.1 V. In electrostatic actuators voltages of up to $100 \mathrm{~V}$ are common. Vertical pull-in has to be anticipated in the design even if thick structures $(10 \mu \mathrm{m})$ and large gap spacings (4 $\mu \mathrm{m})$ are used (figure 10). Pull-in to the substrate can be avoided by electrical shielding in order to give the substrate locally the same potential as the structures directly above. Another approach is to always keep rotor parts at the same voltage as the substrate and to only allow a voltage difference between the stator poles and the substrate. 


\section{Push-down by gravity}

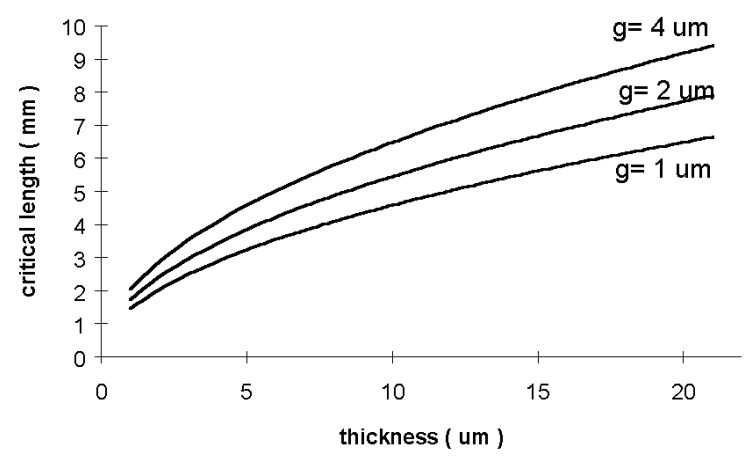

Figure 12. The length of silicon cantilever beams collapsing under their own weight $\left(a=9.8 \mathrm{~m} \mathrm{~s}^{-2}\right)$. At the critical length, the tip just touches the substrate. A Young's modulus of $150 \mathrm{GPa}$ and a density of $2.3 \times 10^{3} \mathrm{~kg} \mathrm{~m}^{-3}$ are assumed.

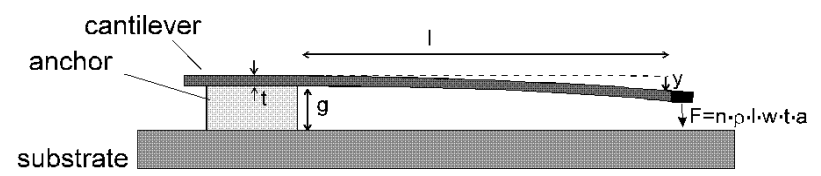

Figure 13. A cantilever beam carrying $n$ times its own mass at the tip. If the substrate is accelerated by $a\left(\mathrm{~m} \mathrm{~s}^{-2}\right)$ upward, the tip is pushed down to the substrate by a force noawtl.

\subsection{Push-down by acceleration forces}

First collapse of a cantilever under its own weight is analyzed. Let us assume that the substrate is accelerated by $a\left(\mathrm{~m} \mathrm{~s}^{-2}\right)$ in an upward direction. This means that a cantilever beam, anchored on the substrate, is pushed down by a force $q$ per unit length of $\rho a w t$, where $\rho$ is the density, $w$ is the width of the beam and $t$ is the thickness of the beam (figure 11).

The tip deflection of the cantilever beam, uniformly loaded by this $q$ is given by

$$
y=\frac{\rho w t a l^{4}}{8 E l} .
$$

$\rho$ is the density, $w$ is the width of the beam, $t$ is the thickness of the beam, $l$ is the length of the beam and $E I$ is the flexural rigidity. By taking the tip deflection as equal to the gap spacing $g$, and substituting $I=t^{3} w / 12$ for the moment of inertia, we can write for the critical length

$$
l_{\text {crit }}=\sqrt[4]{\frac{2}{3} \frac{g t^{2} E}{\rho a}} .
$$

The critical length as a function of the beam thickness for silicon cantilevers undergoing Earth gravitational acceleration is shown in figure 12 .

The critical length of doubly clamped beams is $2^{4} \sqrt{3}$ times larger (neglecting axial stress). For the dimensions evaluated, critical lengths are all larger than $1 \mathrm{~mm}$. Only

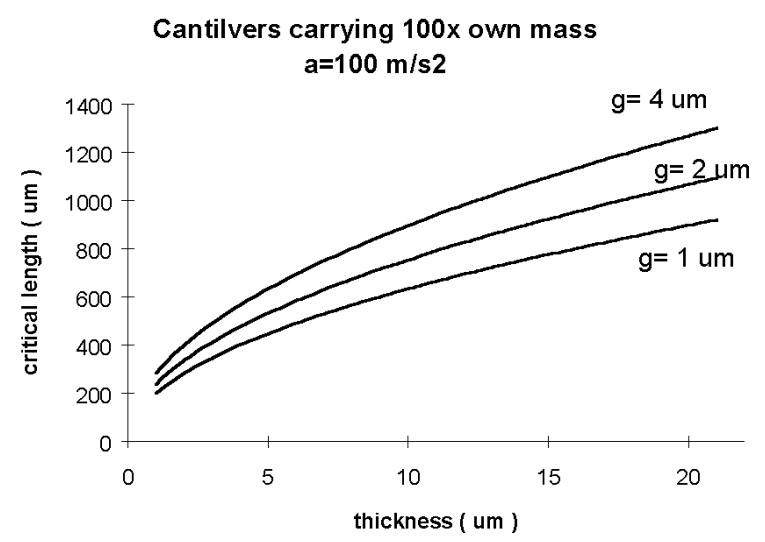

Figure 14. The critical length of silicon cantilever beams carrying 100 times their own mass, undergoing vertical acceleration of $100 \mathrm{~m} \mathrm{~s}^{-2}$, as a function of the thickness $t$, for three different gap spacings $g$. A Young's modulus of $150 \mathrm{GPa}$ and a density of $2.3 \times 10^{3} \mathrm{~kg} \mathrm{~m}^{-3}$ are assumed.

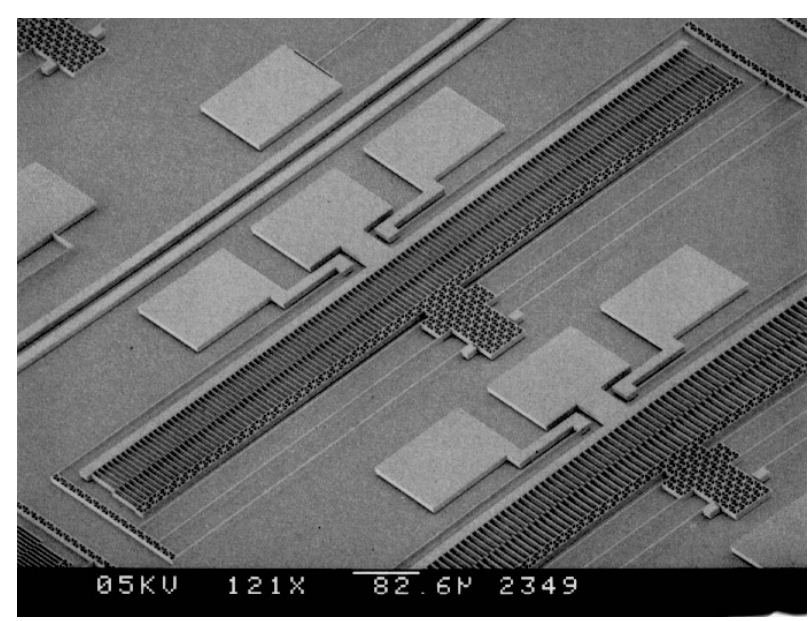

Figure 15. A photograph of a large comb-drive actuator [7]. Support springs are $1 \mathrm{~mm}$ long, and carry a large mass at the tip.

for thin structures, suspended near the substrate, is there a danger of touching the substrate due to gravity. Large structures are often supported by thin flexible springs. In this case, acceleration forces have to be taken seriously, especially if devices have to be shock proof. We therefore analyze a cantilever beam, loaded at its tip by $n$ times its own weight (figure 13).

Let us assume that the substrate is accelerated by $a$ in an upward direction. With reference to the substrate, this can be modeled by loading the cantilever at its tip, by a force of noawtl. The tip deflection $y$ is given by

$$
y=\frac{n \rho t w a l^{4}}{3 E l} .
$$

By taking the tip deflection as equal to the gap spacing $g$, and substituting $I=t^{3} w / 12$ for the moment of inertia, we 
a.

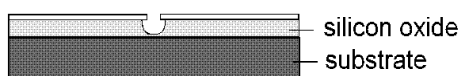

b.

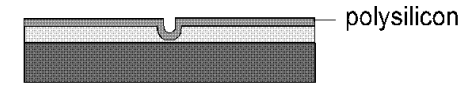

c.

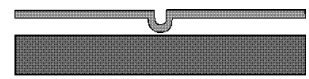

Figure 16. Fabrication of bumps according to [48] and [49]: (a) isotropic etch of hole; (b) deposit of polysilicon structural layer; (c) release etch.

a.

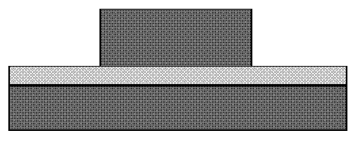

d.

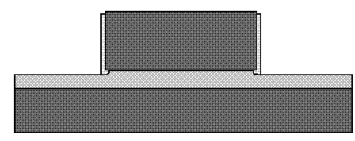

b.

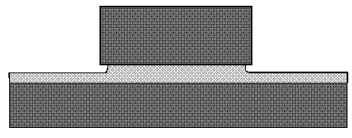

e.

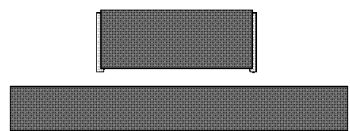

c.

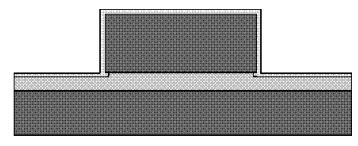

Figure 17. A processing scheme for robust side-wall spacers, starting from (a) patterned silicon structural layer; (b) isotropic thinning of sacrificial layer; (c) growth of anti-stiction silicon nitride layer; (d) anisotropic silicon nitride etch; (e) sacrificial layer etch.

can write for the critical length

$$
l_{\text {crit }}=\sqrt[4]{\frac{g t^{2} E}{4 n \rho a}} .
$$

The critical length of doubly clamped beams is $2 \sqrt{2}$ times larger (neglecting axial stress). Figure 14 shows the critical length of silicon cantilevers, carrying 100 times their own mass, under an acceleration of $100 \mathrm{~m} \mathrm{~s}^{-2}$, which is only a moderate shock.

For thicknesses smaller than about $10 \mu \mathrm{m}$, the critical length is in the region which is often used in elastic suspensions of laterally driven electrostatic devices. Mechanical shock induced contact is difficult to eliminate from these devices.

\section{Stiction reduction of contacting structures}

In section 3 it was shown that an adhesion energy of $100 \mathrm{~mJ} \mathrm{~m}^{-2}$ is high enough to counterbalance restoring elastic forces of short, thick beams. If large structures are supported by narrow beams the stiction forces will be even more dominant. The comb-drive shown in figure 15 is an example of such a structure. Structures like this are also sensitive to applied mechanical shocks. It therefore requires special fabrication procedures and careful handling during its whole life-time. If stiction is to be eliminated in such a large structure, extreme reduction of the adhesion energy is necessary. Low adhesion energy is also desirable in devices where contact between moving parts is essential to the functioning of the device $[5,6]$. Coating and reduction of the RCA is analyzed here.

\subsection{Reducing the adhesion energy}

Coating can have a significant effect if capillary forces or hydrogen bridging are the dominant adhesion mechanisms. By providing a hydrophobic surface, coating can eliminate water mediated adhesion [43,44]. Adhesion by van der Waals forces will always remain. A typical weakly adhesive material such as PTFE still has a surface tension of the order of $20 \mathrm{~mJ} \mathrm{~m}^{-2}$. Other weakly adhesive materials are the typical friction reducing coatings [45-47]. The adhesion energy of perfect flat surfaces will hardly be lower than about $40 \mathrm{~mJ} \mathrm{~m}{ }^{-2}$. Coating alone will not be enough if large reductions of the adhesion energy are desired. Reduction of the RCA should be applied.

\subsection{Reducing the geometrical area contact}

6.2.1. Bumps. Fan et al $[48,49]$ were the first to use stiction reducing bumps. They etched isotropically holes in the sacrificial oxide, before depositing polysilicon (figure 16). These hemispherical bumps reduce the contact area to dimensions smaller than the resolution of the photolithography used.

6.2.2. Side-wall spacers. The use of side-wall spacers to reduce the geometrical area of contact was first reported by Sandejas et al [50]. Due to the self-aligned nature of the process side-wall spacers can be fabricated without additional mask steps. The process can be applied to standard SOI wafers, which is another great advantage. At MESA we have experiments with a process that generates spacers that are grown partly underneath the structures. The process is illustrated in figure 17. After the structural layer has been etched by RIE (figure 17(a)), isotropic etching of the oxide is performed in 5\% BHF, for $3 \mathrm{~min}$. The lateral etch rate of the SOI oxide used is $2-3 \mathrm{~nm} \mathrm{~s}^{-1}$, which is higher than the expected $1 \mathrm{~nm} \mathrm{~s}^{-1}$ for thermal oxide. LPCVD silicon nitride $(150 \mathrm{~nm})$ is grown all around (figure 17(c)). Next, the silicon nitride is etched anistropically in RIE, leaving it on the side-walls and underneath the structure (figure 17(d)). Finally the structure is released in 50\% HF (figure 17(e)).

The spacers obtained are extremely robust. By using a probe pen, structures can be pushed down to the substrate. They can be moved easily across the surface. Even $2 \mu \mathrm{m}$ small beams can be released by simple touching. Without spacers, the same structures stuck heavily and 


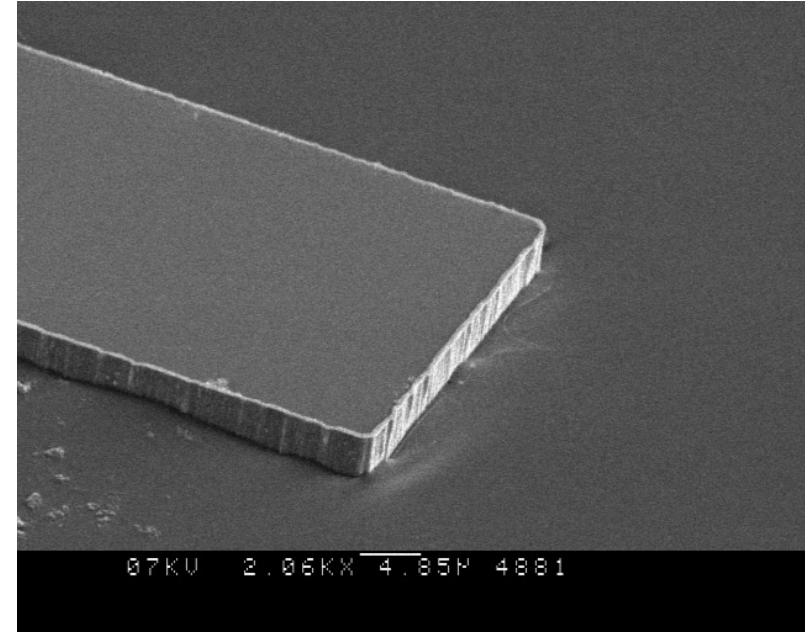

(a)

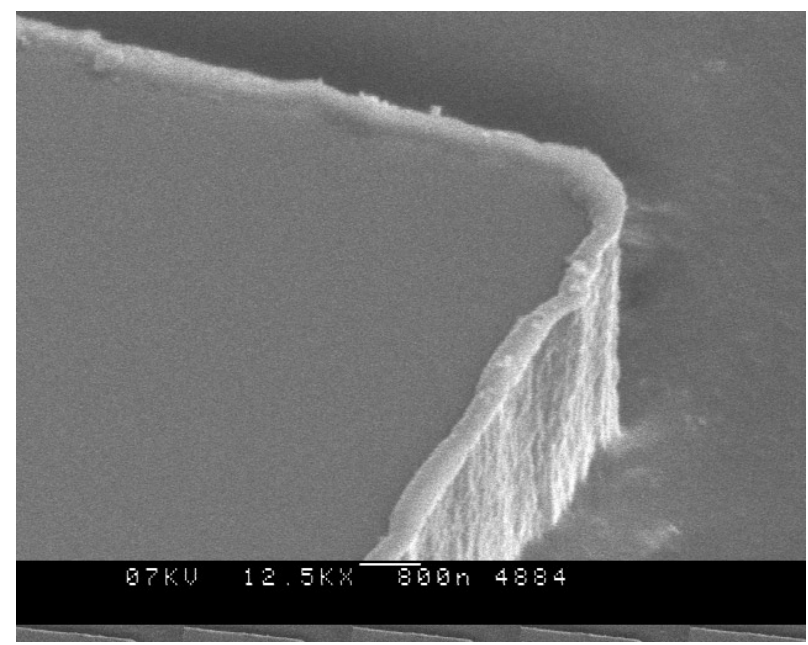

(b)

Figure 18. (a) An SEM photograph of the bottom side of a cantilever beam. (b) A close-up; the width of the spacers is about $500 \mathrm{~nm}$.

could not be released without damage. Spacers are especially useful for experimental devices: beams that stick can be freed easily, and testing can continue. From the initial experiments we learned that side-wall spacers do not entirely eliminate stiction. Therefore, the detachment length of cantilever beams with and without side-wall spacers has been measured. The stiction of beams of three different widths, 12, 24 and $36 \mu \mathrm{m}$, has been measured. The cantilever beams have been fabricated on an SOI wafer having a structural layer thickness of $4.5 \mu \mathrm{m}$ and an oxide layer thickness of $1.0 \mu \mathrm{m}$. Side-wall spacers have been fabricated according to the processing scheme shown in figure 17. Figure 18 shows close ups of the bottom side of a fabricated beam.

The spacers have a width of about $500 \mathrm{~nm}$, due to the higher than expected lateral etch rate of the oxide. In order to obtain stiction, samples have been dried from IPA after the sacrificial layer etching. Detachment lengths have been measured using an optical microscope with the interference contrast method (figure 19), and from SEM photographs.

Measurements have been made on ten cantilevers of

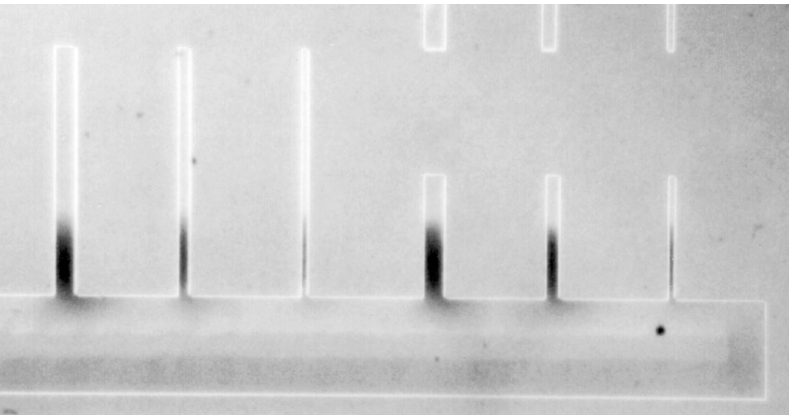

Figure 19. Sticking cantilever beams (the length is $200 \mu \mathrm{m}$ and the widths are 12, 24 and $36 \mu \mathrm{m}$ ) seen through an optical microscope using interference contrast. The dark areas are detached.

each type. Table 2 shows the average detachment length.

An adhesion energy of $0.10 \pm 0.07 \mathrm{~J} \mathrm{~m}^{-2}$ can be calculated for the cantilevers without spacers. From the average detachment lengths, a $2 \times 10^{1}-, 4 \times 10^{1}$ - and $6 \times 10^{1}$ fold reduction for the adhesion energy per unit length of the beam can be calculated using (10). This slightly larger than the reduction of the geometrical contact area due to the side wall spacers, which is 12-, 24- and 36-fold assuming a total spacer width of $2 \times 0.5 \mu \mathrm{m}$. The roughness of the spacers as well as the adhesion energy of the silicon nitride to silicon might explain for the difference. It can be concluded that the side-wall spacers help to reduce the contact area as expected. They are an important aid in the reduction of stiction problems in test devices. Although the contact area is reduced as much as $6 \times 10^{1}$-fold for the widest beams, the critical length is only increased by a factor of 2.8. An additional increase by a factor of about 1.5 in the detachment length should be feasible by making smaller spacers.

6.2.3. Side-wall spacing; supports on substrate. Kozlowski et al [36] have created side-wall spacing in an elegant way. After (dry) release of etched structures (figure 20(a)), fluorocarbon polymers are deposited, partly underneath the structures (figure 20(b)), thus giving robust, low-surface-energy spacers.

As is the case with the temporary supports during drying (see subsection 4.2), the maximum lateral spacing between the bumps is determined by the vertical stiffness of the structures.

\subsection{Increased roughness}

Adhesion of elastic solids due to van der Waals forces is expected to be extremely sensitive to surface roughness $[51,52]$. Fuller and Tabor [51] have tried to model the relation between roughness and adhesion of elastic solids. As in Greenwood and Williamson [53] the rough surface is modeled by asperities all of the same radius of curvature. A Gaussian distribution of their heights is assumed. The overall contact force is obtained by applying the contact theory of Johnson et al [54]. This model describes the influence of the surface energy on contact size and the force of adhesion between two spherical elastic solids in 
Table 2. Measured detachment length for three different beam widths. Beams with and without side-wall spacers are compared.

\begin{tabular}{lll}
\hline & $\begin{array}{l}\text { Cantilever width } \\
(\mu \mathrm{m})\end{array}$ & $\begin{array}{l}\text { Detachment length (average, } n=10) \\
(100 \mu \mathrm{m})\end{array}$ \\
\hline Without spacers & 12 & $1.2 \pm 0.2$ \\
& 24 & $1.2 \pm 0.2$ \\
With spacers & 12 & $1.2 \pm 0.2$ \\
& 24 & $2.6 \pm 0.4$ \\
& 36 & $3.0 \pm 0.4$ \\
\end{tabular}

a.

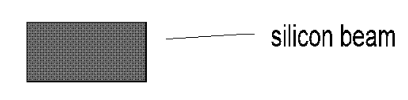

substrate b.

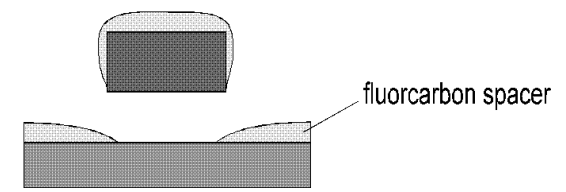

Figure 20. Creation of side-wall spacing [36]: (a) released structure; (b) deposition of fluorocarbon, partly underneath the structure.

contact. Fuller and Tabor define an adhesion parameter. This consists of a composite Young's modulus, the asperity radius, the standard deviation of the asperity heights and the adhesion energy. The adhesion parameter describes the competition between the adhesion force between lower asperities trying to hold the surfaces together and the elastic force exerted by the higher asperities trying to separate the surfaces. The model predicts a sharp decay of the pull-off force, if the roughness is increased beyond a value predicted by the adhesion parameter. This has been verified experimentally for smooth rubber on roughened Perspex [51]. In magnetic recording, a strong dependence of stiction and friction on surface roughness has been measured [55]. Surface roughness modification to reduce stiction of (poly)silicon structures has been shown to be effective [43,56-58]. Reduction of the adhesion energy of at least tenfold are obtained. Houston et al [43] report a work of adhesion value as low as $0.3 \mathrm{~mJ} \mathrm{~m}^{-2}$ after surface treatment with ammonium fluoride. Ammonium fluoride etches the silicon surface, leaving (111) faceted protrusions. The resulting surfaces are hydrogen terminated and hydrophobic. The extreme low work of adhesion may be the result of the combination of roughness and hydrophobicity. Due to the hydrophobic properties of the surface, water mediated adhesion probably is avoided. This should be kept in mind if roughness is increased. In order to receive the full benefit of the reduced RCA by increased roughness, growth of the area of contact by capillary condensation around points of contact should be avoided. In atmospheric conditions where there is a chance of condensation of water this can be achieved by hydrophobic coating. In order to obtain a stable hydrophobic surface coating with fluorocarbon can be a good option [59].

\section{Conclusions}

Stiction research has firstly focused on diminishing the pulldown forces of drying liquid during fabrication. Several methods have been developed that reduce the problems to an acceptable level. We have shown that released structures can come in contact during operation. Two possible causes have been identified: pulling down by electrostatic forces and collapse by acceleration forces. In particular applications, one can design the device so that incidental touching of the substrate is impossible or so that restoring elastic forces are high enough for snap-back. In many applications this is not possible and low adhesion forces are desired to avoid stiction. Strongly reduced adhesion forces are also required in devices where contact between moving parts is essential to the functioning of the device. Reduction of additional forces can be obtained by choosing lowsurface-energy contact materials and by reducing the real contact area. If one looks at practical material properties, lowering of the surface energy is not drastic enough to solve stiction problems in general. Reduction of the real contact area is therefore essential. This can be done by reducing the geometrical contact area (bumps, side-wall spacers), or by increasing the surface roughness. In order to make fail-safe devices, large reductions of adhesion forces are needed. A combination of bumps or side-wall spacers and surface roughness may be needed. For devices that are operated in atmospheric conditions the increase of the surface roughness has to be accompanied by measures that reduce the effect of liquid bridging due to capillary condensation of water.

\section{Acknowledgments}

The authors thank Chenqun Gui for useful discussion on adhesion in wafer bonding, and Bart Vogelzang for valuable discussion on microtribology. Bert Otter, Mark Smithers and Johnny Sanderink are thanked for taking SEM photographs. This work is supported by Philips Research. Part of the work has been sponsored by the Dutch Technology Foundation (STW). 


\section{References}

[1] Guckel H, Sniegowski J J, Christenson T R, Mohney S and Kelly T F 1989 Fabrication of micromechanical devices from polysilicon films with smooth surfaces Sensors Actuators 20 117-22

[2] Mastrangelo C H and Hsu C H 1993 Mechanical stability and adhesion of microstructures under capillary forces-part I: basic theory J. Microelectromech. Syst. 2 $33-43$

[3] Mastrangelo C H and Hsu C H 1992 A simple experimental technique for the measurement of the work of adhesion of microstructures Proc. IEEE Solid-State Sensors and Actuators Workshop (Hilton Head Island, SC, 1992) pp 208-12

[4] Mastrangelo C H and Hsu C H 1993 Mechanical stability and adhesion of microstructures under capillary forces-part II: experiments J. Microelectromech. Syst. 2 $44-55$

[5] Legtenberg R, Berenschot E, Lammerink T and Elwenspoek M 1995 An electrostatic axial gap wobble motor 8th Int. Conf. on Solid-State Sensors and Actuators (Transducers '95) (Stockholm, 1995) pp 404-7

[6] Tas N R, Legtenberg R, Berenschot J W, Elwenspoek M C and Fluitman J H J 1995 The electrostatic shuffle motor Proc. Micromechanics Europe Workshop (Copenhagen, 1995) pp 128-31

[7] Legtenberg R 1996 Electrostatic actuators fabricated by surface micromachining techniques $P h D$ Thesis University of Twente

[8] Roberds B and Farrens S 1995 An AFM study on the roughness of silicon wafers correlated with direct wafer bonding Proc. 3rd Int. Symp. on Semiconductor Waferbonding: Physics and Applications (Reno, 1995) pp 326-41

[9] Ljungberg K 1995 Phenomenology of silicon wafer bonding PhD Thesis Uppsala University

[10] Israelachvili J N 1992 Intermolecular and Surface Forces (London: Academic)

[11] Scheepers P R, Voorthuyzen J A, Olthuis W and Bergveld P 1992 Investigation of attractive forces between PECVD silicon nitride microstructures and an oxidized silicon substrate Sensors Actuators A 30 231-9

[12] Deng K and Ko W H 1992 A study of static friction between silicon and silicon compounds J. Micromech. Microeng. 2 14-20

[13] Rabinowicz E 1965 Friction and Wear of Materials (New York: Wiley)

[14] Matthewson M J and Mamin H J 1988 Liquid mediated adhesion of ultra-flat solid surfaces Mater. Res. Soc. Symp. Proc. 119 87-92

[15] Bhushan B 1990 Tribology and Mechanics of Magnetic Storage Devices (New York: Springer)

[16] Li Y, Trauner D and Talke F E 1990 Effect of humidity on stiction and friction of the head/disk interface IEEE Trans. Magnetics MAG-26 2487-9

[17] Stengl R, Tan T and Gosele U 1989 A model for the silicon wafer bonding process Japan. J. Appl. Phys. 28 1735-41

[18] Spierings G A C M and Haisma J 1991 Diversity and interfacial phenomena in direct bonding Proc. 1st Int Symp. on Semiconductor Wafer Bonding, Science, Technology and Applications (Phoenix, AZ, 1991) pp 18-32

[19] Backlund Y, Hermansson K and Smith L 1992 Bond-strength measurements related to silicon surface hydrophilicity J. Electrochem. Soc. 139 2299-301

[20] Legtenberg R, Tilmans H A C, Elders J and Elwenspoek M 1994 Stiction of surface micromachined structures after rinsing and drying: model and investigation of adhesion mechanisms Sensors Actuators A $\mathbf{4 3} 230-8$
[21] Krupp H 1967 Particle adhesion Adv. Colloid Interface Sci. 1 111-239

[22] Alley R L, Cuan G J, Howe R T and Komvopoulus K 1992 The effect of release-etch processing on surface microstructure stiction Proc. IEEE Solid-State Sensors and Actuators Workshop (Hilton Head Island, SC, 1992) pp 202-7

[23] Anderson K M and Colgate J E 1991 A model of the attachment/detachment cycle of electrostatic micro actuators DCS-Vol. 32, Micromech. Sensors, Actuators, and Systems, ASME 1991 pp 255-68

[24] Israelachvili J N and Tabor D 1972 The measurement of van der Waals dispersion forces in the range 1.5 to $130 \mathrm{~nm}$ Proc. R. Soc. A 331 19-38

[25] Gogoi B P and Mastrangelo C H 1995 Post-processing release of microstructures by electromagnetic pulses 8 th Int. Conf. on Solid-State Sensors and Actuators (Transducers '95) (Stockholm, 1995) pp 214-7

[26] Ohtsu M, Minami K and Esashi M 1996 Fabrication of packaged thin beam structures by an improved drying method Proc. IEEE Micro Electro Mechanical Systems Workshop '96 (San Diego, CA, 1996) pp 228-33

[27] Jansen H V 1996 Plasma etching in microtechnology $P h D$ Thesis University of Twente

[28] Abe T, Messner W C and Reed M L 1995 Effects of elevated temperature treatments in microstructure release procedures J. Microelectromech. Syst. 4

[29] Abe T, Messner W C and Reed M 11995 Effective methods to prevent stiction during post-release-etch processing Proc. IEEE Micro Electro Mechanical Systems Workshop '95 (Amsterdam, 1995) pp 94-9

[30] Kim C-J, Pisano A P, Muller R S and Lim M G 1990 Polysilicon microgripper Proc. IEEE Solid-State Sensor and Actuator Workshop (Hilton Head Island, SC, 1990) pp 48-51

[31] Fedder G K and Howe R T 1991 Thermal assembly of polysilicon microstructures Proc. Micro Electro Mechanical Systems 1991 (Nara, 1991) pp 63-8

[32] Mastrangelo C H and Saloka G S 1993 A dry-release method based on polymer columns for microstructure fabrication Proc. IEEE Micro Electro Mechanical Systems Workshop '93 (Fort Lauderdale, FL, 1993) pp 77-81

[33] Kobayashi D, Kim C and Fujita H 1993 Photoresist-assisted release of movable microstructures Proc. 7th Inth. Conf. on Solid-State Sensors and Actuators (Transducers '93) (Yokohama, 1993) Abstract late news papers pp 14-5

[34] Mulhern G T, Soane D S and Howe R T 1993 Supercritical carbon dioxide drying of microstructures Proc. 7th Int. Conf. on Solid-State Sensors and Actuators (Transducers '93) (Yokohama, 1993) pp 296-9

[35] Orpana M and Korhonen A O 1991 Control of residual stress of polysilicon thin films by heavy doping in surface micromachining Proc. 6th Int. Conf. on Solid-State Sensors and Actuators (Transducers '91) pp 957-60

[36] Kozlowski F, Lindmair N, Scheiter Th, Hierold C and Lang W 1995 A novel method to avoid sticking of surface micromachined structures 8th Int. Conf. on Solid-State Sensors and Actuators (Transducers '95) (Stockholm, 1995) pp 220-3

[37] Shaw K A, Zhang Z L and MacDonald N C 1993 Scream 1: a single mask, single-crystal silicon process for microelectromechanical structures Proc. IEEE Micro Electro Mechanical Systems Workshop '93 (Fort Lauderdale, FL, 1993) pp 155-60

[38] De Boer M, Jansen H and Elwenspoek M 1995 The black silicon method V: a study of the fabricating of movable structures for micro electromechanical systems 8 th Int. Conf. on Solid-State Sensors and Actuators (Transducers '95) (Stockholm, 1995) pp 565-8

[39] Li Y X, French P J, Sarro P M and Wolffenbuttel R F 1995 
Fabrication of a single crystalline silicon capacitive lateral accelerometer using micromachining based on single step plasma etching Proc. IEEE Micro Electro Mechanical Systems Workshop '95 (Amsterdam, 1995) pp 368-73

[40] Hirano T, Furuhata T and Fujita H 1993 Dry releasing of electroplated rotational and overhanging structures Proc. IEEE Micro Electro Mechanical Systems Workshop '93 (Fort Lauderdale, FL 1993) pp 278-9

[41] Tilmans H A C 1993 Micro-mechanical sensors using encapsulated built-in resonant strain gauges $P h D$ Thesis University of Twente

[42] Osterberg P M, Gupta R K, Gilbert J R and Senturia S D 1994 A quantitative model for the measurement of residual stress using electrostatic pull-in of beams Proc. Solid-State Sensor and Actuator Workshop (Hilton Head Island, SC, 1994) pp 184-8

[43] Houston M R, Maboudian R and Howe R T 1995 Ammonium fluoride anti-stiction treatments for polysilicon microstructures 8 th Int. Conf. on Solid-State Sensors and Actuators (Transducers '95) (Stockholm, 1995) pp 210-3

[44] Man P F, Gogoi B P and Mastrangelo C H 1996 Elimination of post-release adhesion in microstructures using thin conformal fluorocarbon films Proc. IEEE Micro Electro Mechanical Systems Workshop '96 (San Diego, CA, 1996) pp 55-60

[45] Deng K, Collins R J, Mehregany M and Sukenik C N 1995 Performance impact of monolayer coating of polysilicon micromotors Proc. IEEE Micro Electro Mechanical Systems Workshop '95 (Amsterdam, 1995) pp 368-73

[46] Zarrad H, Chovelon J M, Clechet P, Jaffrezic-Renault N, Martelet C, Belin M, Perez H and Chevalier Y 1995 Optimization of lubricants for silica micromotors Sensors Actuators A 46/47 598-600

[47] Bhushan B 1996 Nanotribology and nanomechanics of MEMS devices Proc. IEEE Micro Electro Mechanical Systems Workshop '96 (San Diego, CA, 1996) pp 91-8

[48] Fan L-S, Tai Y-C and Muller R S 1988 IC-processed electrostatic micromotors Tech. Digest, IEEE Int. Electron Devices Meeting (San Francisco, CA, 1988) pp 666-9
[49] Fan L S, Tai Y and Muller R S 1989 IC-processed electrostatic micromotors Sensors Actuators 20 41-7

[50] Sandejas F S A, Apte R B, Banyai W C and Bloom D M 1993 Surface microfabrication of deformable grating light valves for high resolution displays Proc. 7th Inth. Conf. on Solid-State Sensors and Actuators (Transducers '93) (Yokohama, 1993) Abstract late news papers pp 6-7

[51] Fuller K N G and Tabor D 1975 The effect of surface roughness on the adhesion of elastic solids Proc. R. Soc. A 345 327-42

[52] Arai F, Andou D and Fukuda T Adhesion forces reduction for micro manipulation based on micro physics Proc. IEEE Micro Electro Mechanical Systems Workshop '96 (San Diego, CA, 1996) pp 354-9

[53] Greenwood J A and Williamsson J B P 1965 Contact of nominally flat surfaces Proc. R. Soc. A 295 300-19

[54] Johnson K L, Kendall K and Roberts A D 1971 Surface energy and the contact of elastic solids Proc. R. Soc. A 324 301-13

[55] Raman V, Tang W T, Jen D and Reith T R 1991 The dependence of stiction and friction on roughness in thin film magnetic recording disks $J$. Appl. Phys. 70 1826-36

[56] Alley R L, Mai P, Komvopoulos K and Howe R T 1993 Surface roughness modification of interfacial contacts in polysilicon microstructures Proc. 7th Int. Conf. on Solid-State Sensors and Actuators (Transducers '93) (Yokohama, 1993) pp 288-91

[57] Yee Y, Chun K and Lee J D 1995 Polysilicon surface modification technique to reduce sticking of microstructures 8th Int. Conf. on Solid-State Sensors and Actuators (Transducers '95) (Stockholm, 1995) pp 206-9

[58] Ando Y, Ino J, Ozaki K, Ishikawa Y and Kitahara T 1996 Friction and pull-off force on silicon surface modified by FIB Proc. IEEE Micro Electro Mechanical Systems Workshop '96 (San Diego, CA, 1996) pp 349-53

[59] Jansen H V, Gardeniers J G E, Elders J, Tilmans H A C and Elwenspoek M C 1994 Applications of fluorocarbon polymers in micromechanics and micromachining Sensors Actuators A 41-41 136-40 